\title{
Tumor de células gigantes na coluna torácica: relato de caso
}

\author{
Wilson Baldino Kanitz', Maiara Piccoli Rodighiero², Alberto Arais Pydd ${ }^{3}$, Marcelo Pasa ${ }^{4}$ \\ Complexo Hospitalar da Universidade Luterana do Brasil (ULBRA), Porto Alegre, RS, Brasil.
}

\section{RESUMO}

Objetivo: Relatar e discutir o caso de um paciente com tumor de células gigantes da nona vértebra torácica com evolução peculiar. Relato do caso: Paciente com dor torácica radicular, detectada lesão na nona vértebra torácica, foi operado e recebeu diagnóstico anatomopatológico de tumor de células gigantes (TCG). Apresentou três recorrências locais, sendo a primeira manejada com reintervenção cirúrgica em dois tempos, na segunda também foi realizada reintervenção cirúrgica, porém com fenolização do sítio cirúrgico, preenchimento com metilmetacrilato e radioterapia pós-operatória. Apresentou semeadura de tumor retroesternal, o qual foi ressecado cirurgicamente, não tendo sido realizada terapia complementar. Uma terceira recorrência foi detectada durante procedimento de correção de falência da artrodese posterior, sendo realizada ressecção da lesão e quimioterapia pós-operatória. Durante o tratamento, desenvolveu imunossupressão e evoluiu para óbito em decorrência de suas complicações. Conclusão: O TCG acometendo a coluna torácica é pouco frequente. Trata-se de uma lesão benigna, agressiva localmente e com comportamento incerto. A ressecção cirúrgica com margens amplas é o tratamento padrão-ouro, porém nem sempre factível, em decorrência da localização da lesão.

\section{PALAVRA-CHAVE}

Tumor de células gigantes. Tumor de coluna. Coluna torácica.

\section{ABSTRACT}

Giant cell tumor of thoracic vertebra: case report

Objective: To report and discuss the case of a patient with giant cell tumor of the ninth thoracic vertebra with peculiar evolution. Case report: $A 32$ year-old male patient, with chest root pain due to a lesion detected at the ninth thoracic vertebra underwent surgery and received pathological diagnosis of giant cell tumor (GCT). He presented three local recurrences: the first being managed with surgical intervention in two stages, the second was also performed with surgical intervention with fenolization of surgical site, filled with methyl methacrylate and postoperative radiotherapy; later, presented retrosternal tumor implant, which was surgically resected without complementary therapy; a third recurrence was detected during correction procedure of bankruptcy of posterior arthrodesis, and resection of the lesion and postoperative chemotherapy. During treatment he developed immunosuppression and died due to complications. Conclusion: GCT involving the thoracic spine is a rare disorder. It is a benign, locally and uncertain aggressive behavior. Surgical resection with wide margins is the gold standard treatment, but not always feasible due to the location of the lesion.

\section{KEYWORD}

Giant cell tumor. Spine tumor. Dorsal spine.

\section{Introdução}

Benigno, mas localmente agressivo, o tumor de células gigantes (TCG) é uma neoplasia primária dos ossos que tem predileção por áreas epifisárias em torno da articulação dos joelhos. Dessa forma, o TCG na coluna vertebral é uma entidade relativamente infrequente, sendo o envolvimento extrassacral ainda mais raro, estimado em 1,3\% a 3,3\%. ${ }^{16}$ Ocorre, predominantemente, na terceira e quarta décadas de vida, sendo mais comum no sexo feminino e na população chinesa. ${ }^{1,10,14,16,19}$

Apresentam comportamento biológico incerto, com ocorrência de recidiva em cerca de $20 \%$ a $34 \%$ dos casos. ${ }^{14}$ Uma vez que praticamente todos os tumores

1 Neurocirurgião do Complexo Hospitalar da ULBRA.

2 Acadêmica de Medicina da Universidade Luterana do Brasil (ULBRA), RS, Brasil.

3 Ortopedista especialista em coluna do Complexo Hospitalar da ULBRA.

4 Cirurgião torácico do Complexo Hospitalar da ULBRA. 
ósseos contêm células gigantes, o diagnóstico dessa lesão requer uma boa correlação clínico-radiológica e uma análise histológica adequada, visando excluir outras lesões ósseas que contenham células gigantes. ${ }^{1,13,14}$

Como a maioria dos pacientes acometidos é jovem, o objetivo terapêutico não se restringe apenas à ressecção tumoral completa, mas também a preservar a função espinal. $\mathrm{O}$ tratamento cirúrgico consiste em curetagem ou ressecção em bloco da lesão com subsequente reconstrução. ${ }^{20}$

Por ser um tumor de comportamento biológico incerto e com vários problemas de manejo, este trabalho objetiva relatar um caso dessa patologia envolvendo a coluna torácica, que teve evolução insólita por sua peculiaridade em recidivar, e discutir as dificuldades do tratamento, que exigiu grande esforço e investimento de uma equipe multidisciplinar.

\section{Relato do caso}

Após avaliação e aprovação pelo plenário do Comitê de Ética em Pesquisa em seres humanos e animais da Universidade Luterana do Brasil, procedeu-se a uma revisão do prontuário do paciente com TCG da nona vértebra torácica, atendido em um hospital de Porto Alegre.

Foram revisados aspectos referentes ao diagnóstico sendo este confirmado por exame anatomopatológico -, tratamentos escolhidos, complicações ocorridas e o manejo destas. Também foram revisadas e descritas imagens digitalizadas dos exames complementares relevantes, realizados pelo paciente ao longo de seu tratamento.

JCSN, 32 anos, masculino, atendido em um hospital de Porto Alegre com quadro de dor no rebordo costal esquerdo há três meses. Estudo radiológico simples sem alterações, sendo o quadro atribuído à dor de natureza muscular. Permaneceu com essa dor a despeito do uso de medicação analgésica e anti-inflamatória. Realizou tomografia computadorizada (TC) de tórax, não focada na coluna vertebral, que evidenciou processo expansivo com lesão lítica do corpo e pedículo esquerdo da nona vértebra torácica (T9) (Figura 1), sendo encaminhado ao serviço de neurocirurgia.

Chegou ao serviço com dor no rebordo costal esquerdo, de natureza radicular e com padrão dermatômico. Realizou ressonância magnética (RM) da coluna torácica, que confirmou o achado tomográfico, além de invasão do canal e certa compressão medular (Figuras 2-A e 2-B). Punção biópsia guiada por TC sugeriu diagnóstico presuntivo de cisto ósseo aneurismático, havendo possibilidade alternativa de TCG, raro em vértebras, não podendo, porém, ser afastada. Angiografia espinhal mostrou "blush patológico" em T10 à direita.

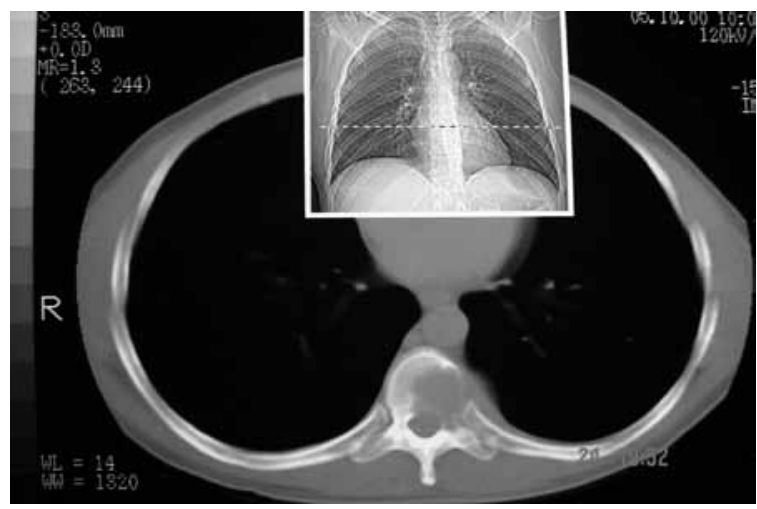

Figura 1-TC de tórax não focada na coluna vertebral evidenciando processo expansivo com lesão lítica do corpo e pedículo esquerdo da nona vértebra torácica.

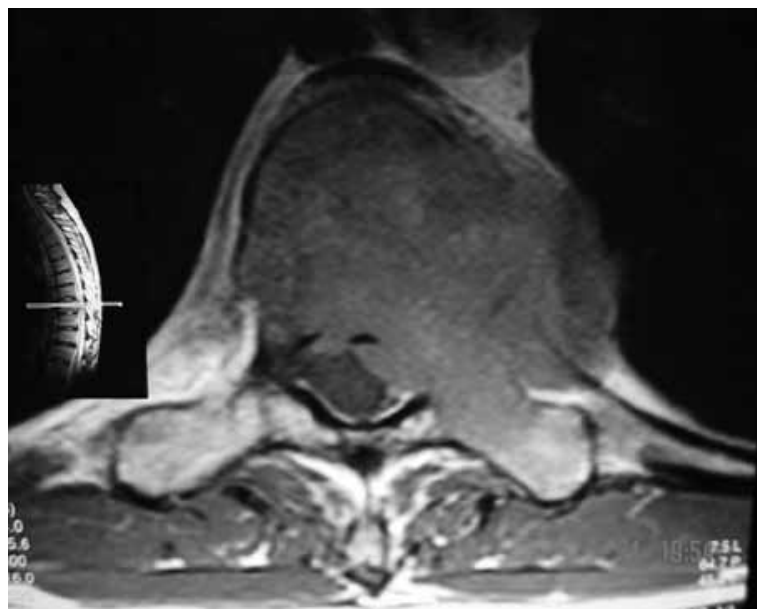

Figura 2-A-RM da coluna torácica evidenciando processo expansivo com lesão lítica do corpo e pedículo esquerdo da nona vértebra torácica.

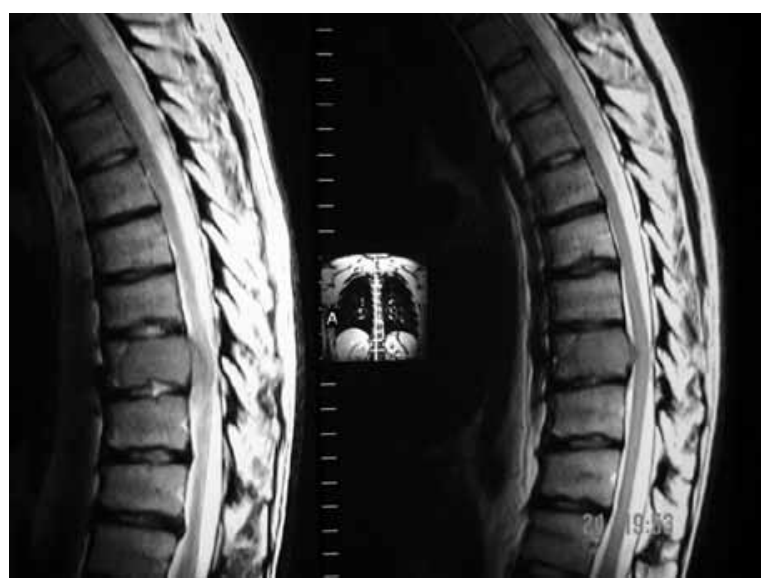

Figura 2-B - RM em corte sagital da coluna torácica evidenciando processo expansivo com lesão lítica do corpo e pedículo esquerdo da nona vértebra torácica apresentando invasão do canal e compressão medular. 
Por piora clínico-neurológica com paraparesia, foi submetido à embolização percutânea pré-operatória com subsequente toracotomia esquerda, hemicorpectomia de T9 esquerda, descompressão medular e artrodese de T8 a T10, com cilindro metálico com enxerto e placa lateral. O exame anatomopatológico foi compatível com TCG. No pós-operatório (PO) imediato, o paciente já mobilizava os membros inferiores; no primeiro $\mathrm{PO}$ apresentava força grau 2-3, evoluindo com melhora progressiva e segurança para deambular. Recebeu alta com revisão e acompanhamento ambulatorial agendado. Terapia complementar foi contraindicada pela oncologia.

Retornou ao serviço, após queda ao solo, no $34^{\circ}$ $\mathrm{PO}$, apresentando síndrome de Brown-Sequárd (déficit motor à esquerda e sensitivo à direita), com boa resposta ao tratamento com corticosteroide. Realizada nova RM que evidenciou recidiva tumoral, ou crescimento e progressão de porção residual, na lâmina e processo transverso à esquerda com extensão paravertebral e no interior do canal raquiano.

Indicadas e realizadas reintervenções cirúrgicas: o primeiro procedimento por via posterior com laminectomia para ressecção dos elementos posteriores, artrodese com retângulo de Hartmann e enxertia posterolateral com costela; o segundo procedimento por toracotomia à direita para completar vertebrectomia total circunferencial (em três tempos) e troca do cilindro interposto na primeira cirurgia, cujo enxerto ósseo era suspeito de estar comprometido pela neoplasia. $\mathrm{O}$ exame anatomopatológico do material recolhido nesses procedimentos confirmou TCG. Apresentando progressiva melhora da força nos membros inferiores e deambulando com auxílio, recebeu alta com plano de seguimento ambulatorial, sendo a terapia complementar contraindicada pela oncologia.

Após seis meses, reinternou com paraparesia e dificuldade de deambular. Suspeitou-se, então, de recidiva tumoral. TC e RM estavam impossibilitadas de visualizar adequadamente o sítio cirúrgico, por causa dos artefatos dos implantes metálicos. Foi realizada, então, uma mielografia, a qual evidenciou obstrução à passagem de contraste no canal medular no nível operado, porém o sítio cirúrgico seguiu de difícil visualização, também em decorrência dos implantes metálicos (Figura 3). Avaliado e discutido o caso com equipe da traumatologia, oncologia e cirurgia torácica, optou-se por reintervenção cirúrgica, fenolização do campo, preenchimento com metilmetacrilato para evitar comprometimento da enxertia óssea e posterior radioterapia, o que foi realizado. O exame anatomopatológico do quarto procedimento cirúrgico mantém diagnóstico de TCG. No PO deste procedimento, também apresentou recuperação completa do déficit neurológico. No PO tardio, apresentou febre persistente mesmo em vigência de antibióticos, sendo reconhecido derrame pleural volumoso. Este evoluiu para empiemas múltiplos
(Figura 4) que culminaram em decorticação pulmonar e, posteriormente, pleurostomia. Apresentando melhora clínica, recebeu alta para realizar radioterapia ( 45 Gy em 5 semanas, 50 sessões) e acompanhamento.

Retornou ao hospital, um ano e dois meses após, apresentando implantação tumoral em mediastino anterior (Figura 5). Foi submetido à toracotomia anterolateral esquerda para ressecção tumoral. Evoluiu com broncopneumonia tardia e, após tratamento, recebeu alta para seguimento ambulatorial, sem indicação de terapia complementar segundo oncologia.

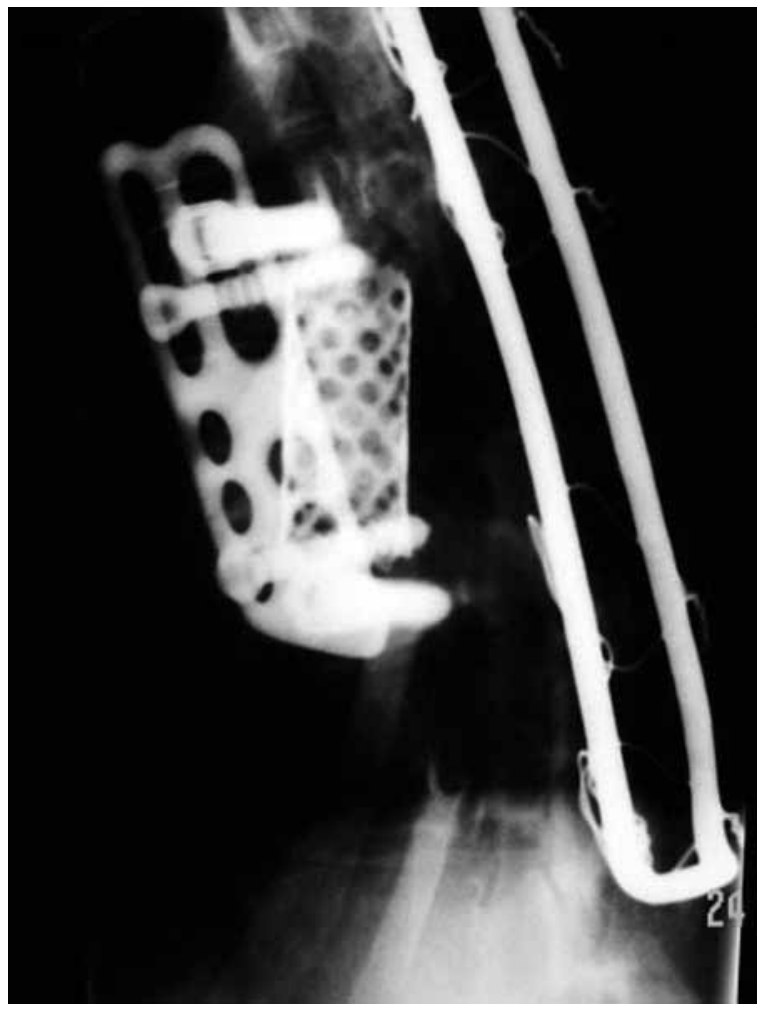

Figura 3 - Mielografia evidenciando obstrução à passagem de contraste no canal medular no nível operado. Sítio cirúrgico de difícil visualização em decorrência dos implantes metálicos.

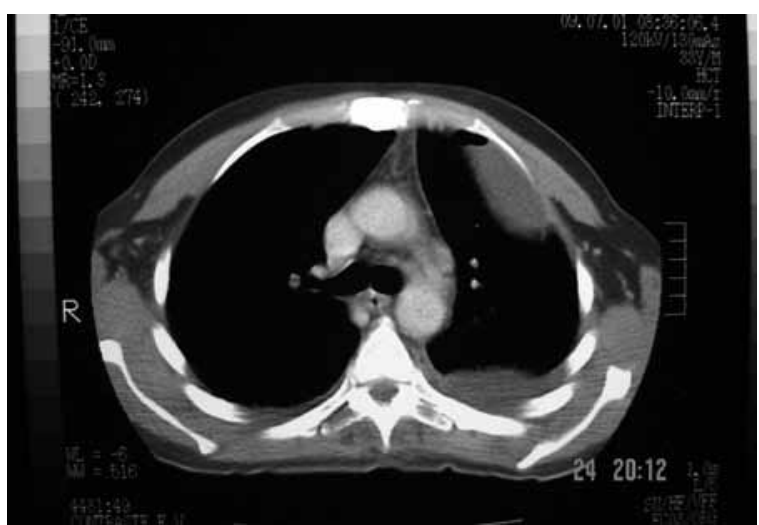

Figura 4-TC de tórax evidenciando empiemas múltiplos. 


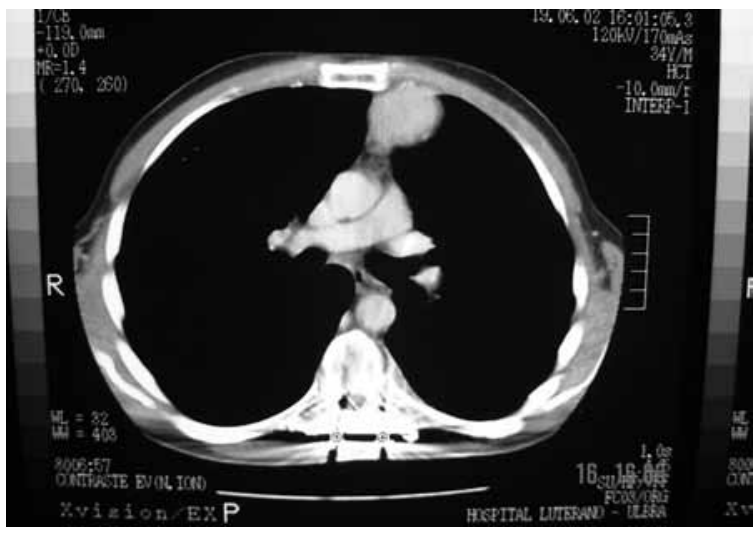

Figura 5-TC de tórax com presença de semeadura tumoral retroesternal.

Após um ano, retornou ao hospital com deformidade torácica e acentuada cifose devida à falência da artrodese posterior, sendo submetido à cirurgia para correção pela via posterior. Durante esse ato cirúrgico, foi reconhecida recidiva tumoral no enxerto de costela posterolateral esquerdo, sendo feita exérese, preenchimento com cimento acrílico e artrodese com ganchos sublaminares acima e parafusos pediculares abaixo da lesão.

Diante de mais essa recidiva, a equipe oncológica indicou tratamento quimioterápico. Durante o longo tratamento, o paciente apresentou imunossupressão e em vigência dessa uma broncopneumonia por Staphylococcus aureus, germe conhecidamente agressivo ao parênquima pulmonar. Durante o manejo da broncopneumonia não respondeu bem ao tratamento, evoluindo com piora clínica e choque séptico; dois meses antes de terminar o tratamento quimioterápico e 18 meses após a última cirurgia, ocorreu o óbito.

\section{Discussão}

O TCG é uma lesão benigna infrequente de natureza mesenquimal, constituída histologicamente por dois tipos de células, as estromais e as células gigantes. ${ }^{1,9}$ As células estromais são mononucleares e citologicamente atípicas; localizam-se no centro da lesão. As células gigantes são estruturas grandes, possuindo de 20 a 30 núcleos e, em sua maioria, compondo a região pericentral da lesão. ${ }^{16}$ Por apresentar características histológicas comuns a diversas lesões tumorais e pseudotumorais, faz-se necessário uma análise clínico-radiólogica conjunta para confirmação diagnóstica. Os principais diagnósticos diferenciais incluem cisto ósseo aneurismático, osteossarcoma teleangectásico e condroblastoma. ${ }^{1}$
Clinicamente, apresentam crescimento lento, porém agressivo localmente, dando sinais e sintomas secundários à compressão de estruturas vizinhas. ${ }^{12,17} \mathrm{O}$ sintoma predominante, que ocorre em mais de dois terços dos pacientes, é a dor, acompanhada de aumento de volume local, sendo esta a principal queixa do paciente em estudo. Sinais como paresia, parestesias, limitação do movimento articular e fratura patológica também são observados. ${ }^{10,11}$ A duração dos sintomas até o momento do diagnóstico pode variar de 3 a 24 meses, sendo em média de 12 meses. ${ }^{6,13}$

Radiologicamente, os TCG são lesões expansivas, bem delimitadas, podendo apresentar adelgaçamento cortical. A imagem em "bolhas de sabão", presente em cerca de $40 \%$ dos tumores, deve-se à formação de septos intratumorais. ${ }^{12,13} \mathrm{Na} \mathrm{TC}$, apresentam-se como uma lesão osteolítica expansiva, com um componente de tecido mole circundado por bordas escleróticas. ${ }^{6} \mathrm{~A}$ RM evidencia uma massa hipointensa em T1 e hiperintensa em T2, com realce heterogêneo após administração de contraste, em decorrência da alta vascularização desse tipo de tumor. ${ }^{12} \mathrm{~A}$ RM é o melhor método para descrever a extensão do tumor e a anatomia de estruturas adjacentes, especialmente em lesões recorrentes. ${ }^{6}$ Porém, ambos os exames apresentam limitações na visualização do sítio tumoral quando são empregados implantes metálicos, por causa dos artefatos de imagem que estes produzem. Em nosso caso, essas restrições foram especialmente vivenciadas quando foi empregado retângulo de Hartmann, incompatível com RM, e fez-se necessária a mielografia, exame invasivo (e por isso não isento de riscos) que por vezes também não proporciona imagens satisfatoriamente esclarecedoras.

Segundo a literatura, o TCG pode ser dividido em três estádios de acordo com sua apresentação radiológica. O estádio 1 ocorre em $10 \%$ a $15 \%$ dos pacientes, corresponde a um TCG latente, assintomático e com bordas escleróticas bem delimitadas. O estádio 2 é encontrado em $70 \%$ dos pacientes, cujos tumores são sintomáticos, geralmente acompanhados de fratura patológica, bem delimitados, com cortical adelgaçada, porém íntegra. $\mathrm{O}$ estádio 3 acomete $10 \%$ a $15 \%$ dos pacientes, sendo de crescimento rápido, associado ou não à fratura patológica, destruição e ruptura da cortical óssea com invasão de estruturas adjacentes. Os três estádios são histologicamente benignos. Essa classificação é de grande importância prognóstica para o paciente, pois os pacientes que apresentam estádio 3 têm maior probabilidade de desenvolver metástases. . $^{10,12,13}$

O TCG localizado na coluna é uma entidade clínico-patológica desafiadora, principalmente no que tange ao tratamento. Várias estratégias foram desenvolvidas para abordagem terapêutica do TCG, incluindo cirurgia, radioterapia, embolização, criocirurgia, nitrogênio líquido e uso de fenol, entre outras. ${ }^{3,20}$ Nenhuma dessas 
estratégias está bem estabelecida, permanecendo o tratamento cirúrgico como o método de eleição. A cirurgia objetiva não somente a ressecção tumoral, como também a diminuição da possibilidade de recorrência local, eliminação da sintomatologia e reconstrução ou manutenção do alinhamento e estabilidade espinal, uma vez que a maioria dos pacientes acometidos por essa patologia é jovem. ${ }^{20}$ Por esse motivo, o grau de investimento tende a ser o máximo, especialmente quando a resposta à cirurgia descompressiva é marcadamente notável, como se evidenciou neste caso, em que o paciente se apresentava severamente paraparético e, após o procedimento cirúrgico, apresentava recuperação plena do déficit.

Hart e cols. ${ }^{4}$ classificaram a extensão da ressecção em: curetagem intralesional e ressecção em bloco, sendo esta dividida em intralesional, marginal e ressecção ampla, com base na extensão da ressecção. Dessa forma, a ressecção em bloco com margens amplas é considerada o tratamento padrão-ouro para tumor de células gigantes, visando à prevenção de recorrência. ${ }^{11,14,15,18}$ De acordo com a graduação radiológica adotada pela literatura, tumor estádio 3 requer cirurgia radical. Alguns autores recomendam curetagem intralesional associada à terapia adjuvante em lesões estádios 1 e 2 e ressecção em bloco para estádio $3 .^{20}$

Quando a ressecção em bloco apresenta muitos riscos ou é inviável em virtude da localização da lesão e sua estreita relação com os elementos neurais, a radioterapia é comumente utilizada no tratamento adjuvante, porém em longo prazo há risco de se desenvolver sarcoma maligno secundário. Por isso, a literatura enfatiza o emprego de radioterapia apenas em lesões incompletamente ressecáveis ou em recorrência tumoral, sendo a dose recomendada de 45 a 50,4 Gy em 1,8 Gy diários. ${ }^{4,12,16}$

Em estudo realizado por Raychaudhuri e cols., ${ }^{16}$ concluiu-se que a alta taxa de recorrência local em fases iniciais está associada a excisão cirúrgica em centro não terciário (83\%), envolvimento de ambos os elementos, anteriores e posteriores (24\%), e extensão para o interior do canal raquiano e para tecidos paravertebrais (21\%). A recorrência local manifesta-se, em média, de três a cinco anos após o tratamento cirúrgico inicial, portanto faz-se necessário seguimento do paciente por esse período de tempo. Durante o seguimento é importante a realização de TC e/ou RM, esta considerada o melhor exame para evidenciar recorrência, capaz de detectar pequenas metástases pulmonares que não podem ser visualizadas no RX de tórax. ${ }^{6,7}$

A recorrência é observada em $20 \%$ a $34 \%$ dos ca$\operatorname{sos},{ }^{14} \mathrm{em}$ sua maioria em pacientes nos quais a cirurgia realizada foi curetagem. ${ }^{10}$ As lesões recorrentes devem ser abordadas com cirurgias mais agressivas, estando a radioterapia indicada. ${ }^{4}$ Estudos sugerem que o uso de fenol, nitrogênio líquido e cimento de metilmetacrilato - este quando empregado de forma tecnicamente correta, de modo que toda a cavidade seja preenchida em sua totalidade e uniformemente - pode reduzir o risco de recorrência para $9 \%{ }^{3}$

Nosso caso evoluiu de forma relativamente insólita, por apresentar uma grande peculiaridade em recidivar, necessitando abordagem multidisciplinar. $\mathrm{Na}$ ocasião da primeira recidiva, optou-se por reintervenção cirúrgica com utilização de enxertia óssea autóloga, que proporciona melhor síntese da artrodese, por ter integração mais rápida, além da vantagem de imunocompatibilidade. ${ }^{1}$ Não se realizou fenolização do campo cirúrgico nesse tempo por receio de edema medular secundário ao processo inflamatório ao álcool. A radioterapia pós-operatória não foi indicada após os primeiros procedimentos também por receio de transformação sarcomatosa e por não se saber, àquela altura, qual seria a evolução do caso. No manejo da segunda recidiva, optou-se por uma abordagem mais agressiva com fenolização do campo e preenchimento com metilmetacrilato, visando diminuir o risco de recorrência. A reação de polimerização desse material é exotérmica, o que pode levar à lise das células neoplásicas. Além disso, o uso do metilmetacrilato, em vez de enxerto autólogo, evitaria confusões em controles futuros quanto a distinguir recidiva com o processo de integração óssea. ${ }^{1}$ No momento da segunda recidiva, discutiu-se a possibilidade de nova recidiva e ponderou-se o risco de malignização e, em decisão conjunta da equipe com o paciente, indicou-se radioterapia complementar.

O TCG apresenta metástases em apenas $1 \%$ a $2 \%$ dos $\operatorname{casos}^{13}$, e alguns autores sugerem que pacientes que tiveram pelo menos um episódio de recorrência local e em tumores radiologicamente agressivos com extensão para partes moles apresentam maior probabilidade de desenvolvê-las. ${ }^{2}$ No caso em estudo, após duas recorrências locais apresentou uma lesão retroesternal, sítio incomum para metástase, visto que esse tipo de tumor produz metástases para o pulmão. Tal localização pode ser indicativa de que essa lesão se tratou de um implante de manipulação cirúrgica ("semeadura cirúrgica"). As lesões metastáticas podem ser únicas ou múltiplas, de crescimento lento, ressecáveis cirurgicamente, eventualmente involuem e possuem bom prognóstico. ${ }^{10,13}$

Durante procedimento cirúrgico realizado para correção de cifose ocasionada por falência da artrodese posterior, identificou-se a terceira recorrência local, sendo esta ressecada. Diante do difícil controle de recorrências locais dessa lesão, indicou-se quimioterapia, mesmo sabendo das poucas referências bibliográficas sobre o seu emprego. ${ }^{12}$ Optou-se por essa terapia complementar também pelo fato de que todas as demais medidas terapêuticas haviam sido esgotadas. 
O cirurgião, individualizando cada caso e em conjunto com o paciente, deve optar entre ressecção radical, quando possível, que acarreta maior morbidade e, em contraponto, menor chance de recidiva, ou excisão subtotal, com menor morbidade, porém com maior risco de recorrência. ${ }^{20}$

\section{Conclusão}

O TCG acometendo a coluna torácica é pouco frequente. Seu diagnóstico requer adequada correlação clínico-radiológica e histológica, pois comporta vários diagnósticos diferenciais.

O tratamento de eleição para os tumores que acometem a coluna é a ressecção cirúrgica em bloco com margens amplas, objetivando reduzir o risco de metástases e recorrência local. Essa abordagem permanece como um desafio ao cirurgião devido à dificuldade de ressecção com margens amplas ocasionada pela estreita relação entre a lesão e estruturas neurológicas importantes. A radioterapia deve ser reservada para os casos recorrentes ou lesões incompletamente ressecáveis.

Até o momento, a maioria dos dados sobre o manejo dessa lesão é baseada em relatos de casos. Para desenvolver princípios sobre a evolução, comportamento e seu tratamento, são necessários estudos multicêntricos. Acreditamos que este trabalho possa contribuir para aumentar a casuística mundial.

\section{Referências}

1. Baptista PPR, Próspero JD, Yonamine ES. Tumor de células gigantes. Rev Bras Ortop. 2001;36:239-44.

2. Bosi TCC, Andrade FCG, Turtelli CM, Ribeiro A, Fatureto MC, Etchebehere RM. Metástase pulmonar de tumor de células gigantes benigno: relato de caso. Radiol Bras. 2008;41:207-9.

3. Camargo OP, Croci AT, Oliveira CRGMC, Baptista AM, Caiero MT. Functional and radiographic evaluation of 214 aggressive benign bone lesions treated with curettage, cauterization, and cementation: 24 years of follow-up. Clinics. 2005;60:439-44.

4. Hart RA, Boriani S, Biagini R, Currier B, Weinstein JN. A system for surgical staging and management of spine tumors: a clinical outcome study of giant cell tumors of the spine. Spine. 1997;22:1773-83.

5. Jesus-Garcia R, Wajchnberg M, Justino MAF, Korukian M, Yshihara HI, Ponte FM. Tumor de células gigantes: análise da invasão articular, fratura patológica, recidiva local e metástase para o pulmão. Rev Bras Ortop. 1997;32:849-56.

6. Junming $M$, Cheng $Y$, Dong $C$, Jianru $X$, Xinghai $Y$, Quan $\mathrm{H}$, et al. Giant cell tumor of the cervical spine. Spine. 2008;33:280-8.

7. Kos CB, Taconis WK, Fidler MW, Ten Velden JJAM. Multifocal giant cell tumors in the spine: a case report. Spine. 1997;22:821-2.

8. $\mathrm{Li} \mathrm{YH}$, Kour AK, Pho RWH. Giant cell tumor of lumbar vertebra: a case report with 13-year follow-up. Clin Orthop. 1998;353:218-22

9. Llanos J, García C, Oyanedel R, Villanueva E, Otero $\mathrm{J}$, Fortune $\mathrm{J}$, et al. Estudio radiológico simple en el diagnostico del tumor de células gigantes en población pediátrica: correlación anatomoradiológica. Rev Chil Radiol. 2008;14:62-7.

10. López AA, Lorenzo YG, Baesso E, Estenoz OQ. Tumor de células gigantes: revisión del tema. Arch Méd Camaguey. 2003;7:1-5.

11. Luther N, Bilsky MH, Härtl R. Giant cell tumor of the spine. Neurosurg Clin N Am. 2008;19:49-55.

12. Martínez DF, Casasco JP, Bonis C, Berner SI. Tumor de células gigantes da base do cráneo: reporte de 2 casos y revisión de la bibliografia. Rev Argent Neurocir. 2007;21:117-9.

13. Garza NJM, Ceccopieri CA, Ortiz HC, Rodríguez LRD, Macías RM. Tumor de células gigantes de hueso: aspectos generales de 11 casos. Rev Med Hosp Gen Mex. 1999;62:240-4.

14. Oliveira CRGCM, Brasile R, Camargo OP, Zerbini MCN, Lula DAAM, Saito CF, et al. A correlação entre exame de imagem, características anatomopatológicas e imunoistoquímicas num caso de tumor de células gigantes agressivo do osso, com localização em coluna. Acta Ortop Bras. 2006;14:170-2 .

15. Ozaki T, Liljenqvist U, Halm H, Hillmann A, Gosheger G, Winkelmann W. Giant cell tumor of the spine. Clin Orthop. 2002;401:194-201.

16. Raychaudhuri R, Gore P, Webb M, Dickman CA. Management of vertebral giant cell tumor with complete spondylectomy: case report. Barrow Quarterly. 2006;22:4-7.

17. Sakurai H, Mitsuhashi N, Hayakawa K, Niibe H. Giant cell tumor of the thoracic spine simulating mediastinal neoplasm. AJNR. 1999;20:1723-6.

18. Smartzis D, Foster WC, Padgett D, Shen FH. Giant cell tumor of the lumbar spine: operative management via spondylectomy and short-segment, 3-column reconstruction with pedicle recreation. Surg Neurol. 2008;69:138-42.

19. Swanger R, Maldjian C, Murali R, Tenner M. Three cases of benign giant cell tumor with unusual imaging features. Clin Imaging. 2008;32:407-10.

20. Yang $S$, Chen L, Fu T, Lai P, Niu C, Chen W. Surgical treatment for giant cell tumor of the thoracolumbar spine. Chang Gung Med J. 2006;29:71-8.

\section{Endereço para correspondência}

Wilson Baldino Kanitz

Av. Alberto Bins, 392, cj. 1303

90030-140-Porto Alegre, RS, Brasil

E-mail:wilsonkanitz@hotmail.com 